\title{
Impaired detection of chemical alarm cues by juvenile wild Atlantic salmon (Salmo salar) in a weakly acidic environment
}

\author{
Antoine Olivier Henri Claude Leduc, Ellie Roh, Mark Charles Harvey, and Grant \\ Edwin Brown
}

\begin{abstract}
Many prey fishes rely on damage-released chemical alarm cues to detect and avoid predators. The ability to use these cues has been shown to confer considerable survival benefits to individuals. While several laboratory studies and a single field study have demonstrated that an ambient $\mathrm{pH}$ of 6.0 impairs fishes in their ability to detect these alarm cues, no study had yet compared the response to alarm cue exposures across populations residing in multiple streams of a different acidity level. In our study, we conducted live behavioural observations in five nursery streams, ranging in $\mathrm{pH}$ from 5.71 to 7.49 on two age classes (young of the year and parr) of wild juvenile Atlantic salmon (Salmo salar). We aimed to assess if the detection of these chemical alarm cues was constantly dependant on the ambient $\mathrm{pH}$ or if variations in the detection occurred among populations of the different streams regardless of the ambient acidity level. Our results demonstrated that salmon present in any acidic stream did not respond to alarm cues, while those in neutral streams exhibited typical alarm responses.
\end{abstract}

Résumé : Plusieurs poissons proies utilisent les signaux d'alerte chimiques libérés par les blessures pour détecter et éviter les prédateurs. Il a été démontré que la capacité d'utiliser ces signaux procure aux individus des bénéfices significatifs de survie. Bien que plusieurs études de laboratoire et une seule étude de terrain aient prouvé qu'un pH ambiant de 6,0 compromet la capacité des poissons à percevoir ces signaux d'alerte, aucune recherche n'a encore comparé les réactions à la présence des signaux d'alerte dans une gamme de populations habitant des cours d'eau avec des niveaux différents d'acidité. Dans notre travail, nous avons mené des observations comportementales en nature dans cinq cours d'eau d'élevage dont les pH variaient de 5,71 à 7,49 chez deux classes d'âge (jeunes de l'année et tacons) de jeunes saumons atlantiques (Salmo salar) sauvages. Nous tentons de déterminer si la perception de ces signaux chimiques d'alerte dépend à tout coup du $\mathrm{pH}$ ambiant ou s'il existe des variations entre les populations des différents cours d'eau indépendantes des niveaux ambiants d'acidité. Nos résultats démontrent que tous les saumons qui habitent les cours d'eau acides ne réagissent pas aux signaux d'alerte, alors que ceux des cours d'eau neutres montrent des réactions typiques d'alerte.

[Traduit par la Rédaction]

\section{Introduction}

Acidification of freshwater ecosystems has considerable impacts on aquatic communities worldwide (Schindler 1988; Guerold et al. 2000). While in the past two decades anthropogenic acidic deposition has decreased by $30 \%-40 \%$ in many industrialized countries (Stoddard et al. 1999), weakly acidic water bodies ( $\mathrm{pH} \sim 5.5-6.0)$ are still widespread (Mallory et al. 1998; Jeffries et al. 2000; Doka et al. 2003). In fishes, acidification is known to induce behavioural changes such as increased area avoidance (Johnson and Webster 1977; Åtland 1998), inhibition of migration (Ikuta et al. 2001), inhibition of spawning (Kitamura and Ikuta 2001), reduced feeding (Lacroix et al. 1985), and impairment of chemosensory risk assessment (Brown et al. 2002;
Leduc et al. 2004a, 2004b). Several of these behavioural changes may represent sublethal effects of anthropogenic acidification. Despite its frequent occurrence, most studies investigating the effect of acidification on fish behaviour have concentrated on intermediate to severe acidification (pH value between 4.0 and 5.5; Lacroix et al. 1985; Gunn and Noakes 1986; Peterson et al. 1989), while the effects of weak acidification ( $\mathrm{pH}$ of 6.0) has received much less attention (but see Ikuta et al. 2001). An acidification level of pH 6.0 corresponds to a threshold under which damage to aquatic biota will represent a major environmental problem (Holt et al. 2003).

A wide variety of aquatic vertebrates rely on chemosensory information to assess and avoid local predation risks (Smith 1992, 1999). Such risk assessment is mediated

Received 18 January 2006. Accepted 16 June 2006. Published on the NRC Research Press Web site at http://cjfas.nrc.ca on 3 October 2006.

J19115

A.O.H.C. Leduc, ${ }^{1}$ E. Roh, M.C. Harvey, and G.E. Brown. Department of Biology, Concordia University, 7141 Sherbrooke St. West, Montréal, QC H4B 1R6, Canada.

${ }^{1}$ Corresponding author (e-mail: aleduc@alcor.concordia.ca). 
through the release and detection of chemical cues in the water column (Chivers and Smith 1998; Wisenden 2000). One extensively studied group of such chemicals is the damage-released alarm cues (reviewed in Chivers and Smith 1998; Brown 2003). These cues are present in the epidermis of taxonomically diverse prey fishes and typically enter the water column following mechanical damage to the skin, as would likely occur during a predation event (Brown and Smith 1997; Chivers et al. 1996). Alarm cues have been studied in several species of salmonids, including brook trout (Salvelinus fontinalis; Mirza and Chivers 2000, 2001a), brown trout (Salmo trutta; Mirza and Chivers 2001a), rainbow trout (Oncorhynchus mykiss; Mirza and Chivers 2001a; Leduc et al. 2004a), and Chinook salmon (Oncorhynchus tshawytscha; Berejikian et al. 1999). Their detection by nearby conspecifics and some sympatric, heterospecific prey-guild members may elicit a suite of short-term, antipredator, behavioural responses, including decreased activity level, increased use of shelter, and increased area avoidance (Smith 1992, 1999). Prey individuals responding to alarm cues have been shown to gain increased survival during staged encounters with live predators (Mirza and Chivers 2000, 2001b, 2003).

The ability to detect and respond to these critically important chemosensory cues may be impaired under acidic conditions. For example, Brown et al. (2002) demonstrated in a laboratory experiment that a weak level of acidification $(\mathrm{pH}$ of 6.0) renders two ostariophysan species, fathead minnow (Pimephales promelas) and finescale dace (Phoxinus neogaeus), unable to detect and respond to conspecific alarm cues. A similar loss of function of chemical alarm cues has been demonstrated for juvenile pumpkinseed (Lepomis gibbosus; Leduc et al. 2003) and rainbow trout (Leduc et al. 2004a). In all cases, the loss of response does not appear to be due to physiological damage to cue receptors, but rather to changes of the alarm cue molecule itself (Brown et al. 2002; Leduc et al. 2004b).

Laboratory conditions, however, lack the ecological relevance of the challenges prey individuals face in their natural habitat, and elements of controversy exist regarding the function of chemical alarm cues under natural conditions (see Magurran et al. 1996; Smith 1997). While several recent studies have shown that various prey fishes do rely on chemical alarm cues to assess risk under natural conditions (Brown et al. 1997; Wisenden et al. 2004), only a single field investigation has examined the potential effects of stream water acidification on the use of these cues. Leduc et al. (2004a) have shown that in a stream of mean $\mathrm{pH} 6.88$, conspecific alarm cue injections elicited a major increase in antipredator response in brook trout compared with a control stimulus. However, in a stream of mean $\mathrm{pH} 6.11$, no change in response was observed following injections of the chemical alarm cues. Population and strain-dependant variations in acid tolerance exist in many fish species, including salmonids (Robinson et al. 1976; Rosseland et al. 2001). While some strains may be adequately suited to live in more acidic conditions, others may suffer increased physiological stress leading to suboptimal behaviour (Åtland 1998). Thus, studying a single population at each acidity level cannot exclude the possibility that differences in alarm response may be the result of population differences in overall physiologi- cal condition and (or) olfactory sensitivity rather than from a direct loss in chemical alarm function. Thus, the general ecological relevance of the effects of weak acidification on chemosensory assessment of damage-released alarm cues remains difficult to assess.

In this study, we assess if the alarm response to conspecific chemical cues of juvenile wild Atlantic salmon (Salmo salar) is correlated with the ambient $\mathrm{pH}$ in nursery streams not directly disturbed by human activities (with the potential exception of acid precipitation). We test in young of the year (YOY; 0+) and parr (1+) for the presence of an alarm response following the exposure to chemical alarm cues in streams of different $\mathrm{pH}$. If a loss of function of chemical alarm cues is linked to alterations of the alarm cue itself rather than population differences in acid tolerance, we predict that prey fish present in any of the acidic streams should show a reduced alarm response compared with fish present in neutral streams. Likewise, we would expect no difference in overall response intensity among populations present in streams of a similar acidity level.

We chose juvenile Atlantic salmon to investigate these questions owing to its territorial and site fidelity behaviour (Grant et al. 1998; Steingrimsson and Grant 2003), allowing for visual observations to be conducted with ease in its habitat. We compared four typical behavioural changes associated with antipredation response (see below) for two year classes (YOY and parr) in six sites of five different streams ranging in acidity from $\mathrm{pH} 5.74$ to 7.33 .

\section{Material and methods}

\section{Test sites}

This experiment was conducted in Northcumberland County, New Brunswick, Canada, in five different streams (Catamaran Brook, Little Southwest Miramichi River, Otter Brook, Devil's Brook, and Correy Creek) between 14-29 of June and 7-23 of August 2003. In these streams, a site of $\sim 50 \mathrm{~m}$ in length (Fig. 1) was chosen for its physical characteristics (canopy cover, distance from the riverbank, and substrate type; Table 1). Because Corey Creek is a tributary of Devil's Brook, we chose to subdivide Devil's Brook into two test sites: one above and one below the mouth of Correy Creek. These two sites on Devil's Brook (named Devil's Brook "High", Devil's Brook "Low", respectively) had two distinct mean $\mathrm{pH}$ values (one-way analysis of variance, $p<0.05$ ) but were otherwise similar it their physical characteristics (Table 2).

After each trial, the $\mathrm{pH}$ and water temperature were recorded (using a portable Accumet ${ }^{\circledR}$ EW-59333-20 pH meter), as well as the surface current speed (using a Flo-Mate velocity meter; Marsh McBirney Inc.), the depth (using a $1 \mathrm{~m}$ ruler), the cloud cover, and the canopy cover. The cloud cover was estimated by the same observer throughout the entire experiment by assessing the percentage of sky that was covered by clouds. The canopy cover was determined by estimating the proportion of sky that was blocked by branches and trees directly above the point of stimulus injection in a $2 \mathrm{~m}$ radius. Overall, test sites were grouped in two distinct categories, neutral or acidic, as a function of their mean $\mathrm{pH}$ (Table 1). Catamaran Brook, Little Southwest Miramichi River, and Otter Brook were considered neutral ( $\mathrm{pH}$ range of 
Fig. 1. The location of the study sites in New Brunswick, Canada. The inset map in the top right corner shows the location of the study sites within New Brunswick. The numbers 1-6 correspond to the study sites (each $\sim 50 \mathrm{~m}$ in length) located on Catamaran Brook, Otter Brook, Little Southwest Miramichi River, Devil's Brook "High”, Devil's Brook "Low", and Correy Creek, respectively.

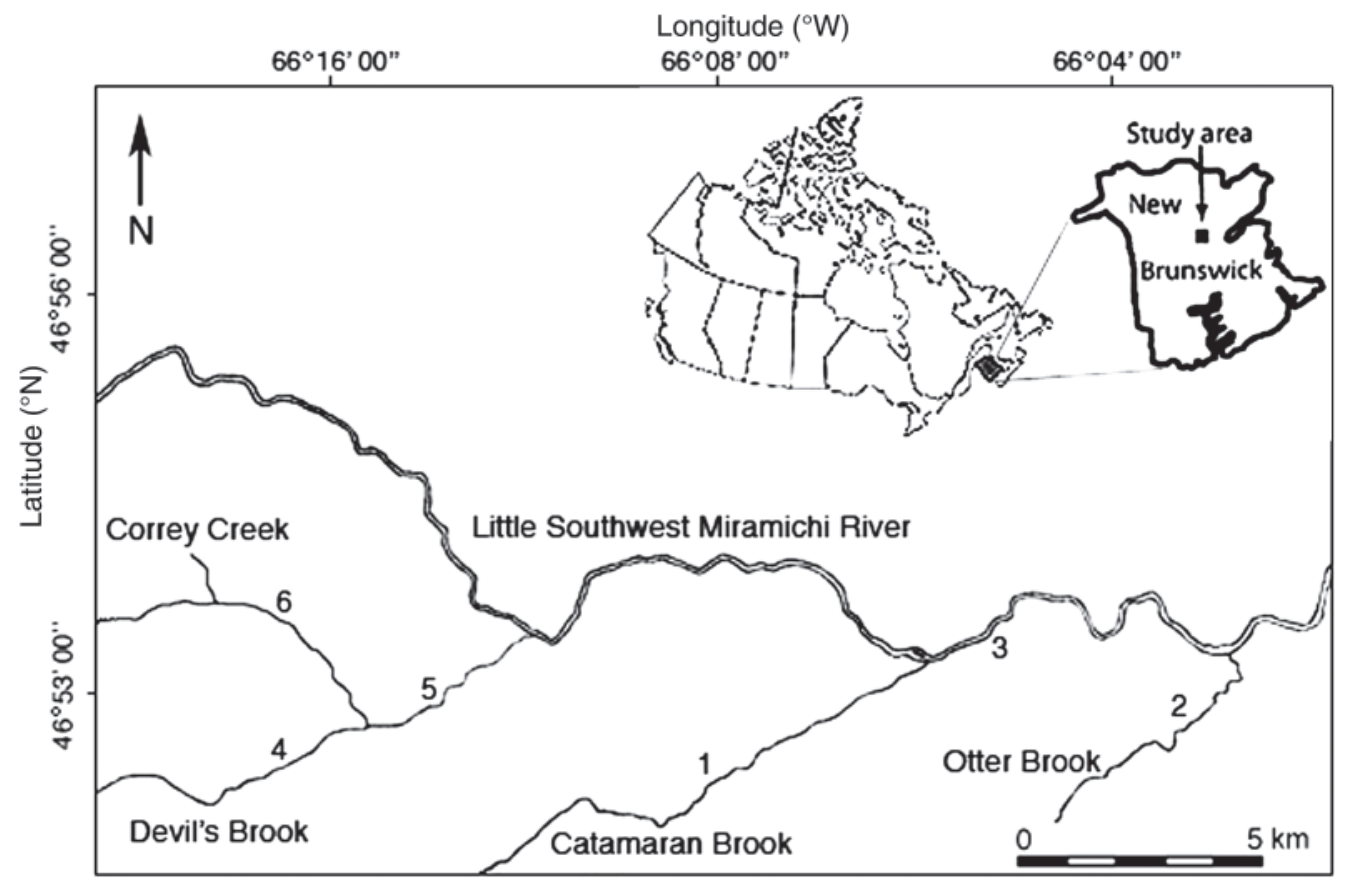

Table 1. Mean ( \pm standard deviation) values for the physical and chemical variables of the studied streams.

\begin{tabular}{|c|c|c|c|c|c|c|}
\hline Stream & $\mathrm{pH}$ & $\begin{array}{l}\text { Water temperature } \\
\left({ }^{\circ} \mathrm{C}\right)\end{array}$ & $\begin{array}{l}\text { Current velocity } \\
\left(\mathrm{cm} \cdot \mathrm{s}^{-1}\right)\end{array}$ & $\begin{array}{l}\text { Canopy cover } \\
(\%)\end{array}$ & $\begin{array}{l}\text { Cloud cover } \\
(\%)\end{array}$ & $\begin{array}{l}\text { Depth } \\
(\mathrm{cm})\end{array}$ \\
\hline Catamaran Brook & $7.25 \pm 0.17$ & $17.0 \pm 0.5$ & $52.3 \pm 18.9$ & $63.0 \pm 20.0$ & $43.2 \pm 12.7$ & $37.0 \pm 11.8$ \\
\hline Little Southwest Miramichi & $7.16 \pm 0.07$ & $16.7 \pm 0.6$ & $69.9 \pm 18.2$ & $12.5 \pm 3.4$ & $19.6 \pm 21.4$ & $51.7 \pm 11.3$ \\
\hline Correy Creek & $6.03 \pm 0.06$ & $17.7 \pm 1.2$ & $40.3 \pm 11.1$ & $74.3 \pm 18.2$ & $33.8 \pm 17.9$ & $34.0 \pm 6.8$ \\
\hline Devil Brook "High" & $5.85 \pm 0.12$ & $15.8 \pm 1.0$ & $35.3 \pm 19.7$ & $57.9 \pm 17.6$ & $56.1 \pm 12.3$ & $28.4 \pm 7.8$ \\
\hline
\end{tabular}

Table 2. Mean value ( \pm standard deviation) of the physical and chemical variables between the neutral and acid sites for June and August.

\begin{tabular}{llllll}
\hline Variable & Neutral & Acidic & $F$ & df & $P$ \\
\hline June & & & & & \\
pH & $7.11 \pm 0.19$ & $5.88 \pm 0.10$ & 149.83 & 6,9 & 0.001 \\
Water temperature $\left({ }^{\circ} \mathrm{C}\right)$ & $16.8 \pm 0.62$ & $16.9 \pm 1.74$ & 0.104 & 6,9 & 0.748 \\
Canopy cover $(\%)$ & $49 \pm 30$ & $57 \pm 23$ & 7,673 & 6,9 & 0,070 \\
Cloud cover $(\%)$ & $26 \pm 19$ & $34 \pm 27$ & 0.403 & 6,9 & 0.528 \\
Velocity $\left(\mathrm{cm} \cdot \mathrm{s}^{-1}\right)$ & $54 \pm 18$ & $45 \pm 16$ & 0.867 & 6,9 & 0.355 \\
Depth $(\mathrm{cm})$ & $42 \pm 10$ & $36 \pm 16$ & 0.097 & 6,9 & 0.756 \\
August & & & & & \\
pH & $7.16 \pm 0.04$ & $6.04 \pm 0.06$ & 767.76 & 6,9 & 0.002 \\
Water temp $\left({ }^{\circ} \mathrm{C}\right)$ & $16.4 \pm 0.77$ & $17.3 \pm 0.84$ & 2.975 & 6,9 & 0.089 \\
Canopy cover $(\%)$ & $47 \pm 28$ & $56 \pm 21$ & 0.969 & 6,9 & 0.328 \\
Cloud cover $(\%)$ & $33 \pm 16$ & $36 \pm 20$ & 0.337 & 6,9 & 0.564 \\
Velocity $\left(\mathrm{cm} \cdot \mathrm{s}^{-1}\right)$ & $50 \pm 22$ & $41 \pm 14$ & 1.963 & 6,9 & 0.166 \\
Depth $(\mathrm{cm})$ & $38 \pm 16$ & $32 \pm 8$ & 1.706 & 6,9 & 0.196 \\
\hline
\end{tabular}

Note: One-way analysis of variance (ANOVA) was used to assess differences among groups of neutral and acidic streams for the surveyed variables. 
6.96-7.33), while Devil's Brook “High”, Devil's Brook "Low", and Corey Creek were considered acidic ( $\mathrm{pH}$ range of 5.74-6.09). With the exception of the $\mathrm{pH}$, no significant difference between the measured characteristics of the two groups of test sites was found (Table 2). Also, there was no significant difference in mean $\mathrm{pH}$ in each respective group of streams (neutral or acidic) between June and August (Table 2).

\section{Stimulus collection}

Skin from Atlantic salmon was collected as a source of the alarm cue substance on 13 June and 5 August 2003 from Little Southwest Miramichi River. Less than an hour after their capture, these Atlantic salmon were killed with a single blow on the head (in accordance to Concordia Animal Care Committee Protocol AC-2002-BROW), and skin fillets from both sides of their body were removed and immediately placed into an ice-chilled container filled with stream water of pH 7.04 and 7.08 (June and August, respectively). In June, we collected $327.74 \mathrm{~cm}^{2}$ and $332.21 \mathrm{~cm}^{2}$ of skin (parr and YOY, respectively), while in August we collected $348.21 \mathrm{~cm}^{2}$ and $319.80 \mathrm{~cm}^{2}$ of skin (parr and YOY, respectively). Fillets were homogenized and diluted with stream water, producing alarm cue solutions ranging from 0.150 to $0.158 \mathrm{~cm}^{2} \cdot \mathrm{mL}^{-1}$.

This procedure has been shown to elicit a consistent antipredator response in cyprinids (Brown et al. 2002), in centrarchids (Leduc et al. 2003), and in salmonids (Brown and Smith 1997, 1998; Mirza and Chivers 2002). The resulting solution was frozen in $25 \mathrm{~mL}$ aliquots at $-20{ }^{\circ} \mathrm{C}$ until needed. As a control, stream water was also frozen in $25 \mathrm{~mL}$ aliquots.

\section{Experimental protocol}

Field observations were conducted between 15-29 of June and 7-29 of August 2003 using the method of Leduc et al. (2004a) (modified from Steingrimsson and Grant 2003). Observation trials were conducted on focal test fish (found while snorkeling on the test sites) from $\sim 1.5 \mathrm{~m}$ upstream from the test fish, at an angle of $45^{\circ}$ relative to water current. This positioning was used to minimize visual obstruction of the focal fish and to reduce interference from drifting particulate matter. To ensure that the fish was behaving normally (i.e., it had resumed feeding and moving), it was left to acclimate to the observer's presence for a minimum of 2 min before any observations were recorded. Trials were $20 \mathrm{~min}$ in length and divided in $10 \mathrm{~min}$ pre-stimulus injection and $10 \mathrm{~min}$ post-stimulus injection periods. After the first $10 \mathrm{~min}$ elapsed (pre-stimulus), the observer injected the stimulus (either stream water or alarm cue solution for the control or experimental treatments, respectively) using a $60 \mathrm{~mL}$ syringe at a constant rate of $6 \mathrm{~mL} \cdot \mathrm{s}^{-1}$. The stimulus was injected approximately $1-1.5 \mathrm{~m}$ upstream of the test fish. The experimental treatment order and the year-class subjects were completely randomized, while the overall order of the test sites surveyed was partially randomized. All trials were conducted and videotaped by the same observer using an underwater Sea View ${ }^{\circledR}$ camera. As the camera was located between 1 and $1.5 \mathrm{~m}$ from the focal test fish, small-scale behavioural response could easily be monitored. In total, 144 trials were conducted (six replicates per treatment in six sites with two year classes). Each trial was conducted on a single fish that was used only once. To ensure that our injected stimulus reached our test fish, dye injection tests (commercial 2\% milk) were conducted. These tests were done after the completion of 16 randomly assigned experimental trials in which the same experimental protocol was used. For all dye injection trials, the injected dye reached the test fish, suggesting that our injected stimuli were also reaching our test fish. Smith (1999) reported that a single exposure to alarm cue was sufficient to elicit an alarm response.

\section{Behavioural measures}

To assess the intensity of an alarm response from exposure to a stimulus as well as to increase our power of detection, five behavioural modalities were quantified: the number of feeding attempts, the number of aggressive interactions, the total time spent in motion (in seconds), the total time spent motionless on the substrate (in seconds), and the total time spent absent (in seconds). These behavioural responses were quantified by viewing videotapes on a 14-inch $(35 \mathrm{~cm})$ Toshiba $^{\mathrm{TM}}$ flat screen monitor. All trials were viewed twice by the same observer. We chose these above-mentioned behavioural measures, as they allow us to gauge the alarm response intensity in several fish species (Leduc et al. 2004a; Mirza and Chivers 2002; Wisenden et al. 2004) and may confer survival benefits to individuals during predator encounters (Mirza and Chivers 2003). A feeding attempt was defined as a movement of at least half a body length toward a drifting particle or a particle on the substrate and where a biting attempt occurred. An aggressive interaction was defined as a movement of at least a body length toward another fish with or without a biting attempt. Time in motion was measured when an individual was changing its location by at least a body length. The time on substrate was measured when an individual was laying on the substrate without changing its location. Finally, the time absent was defined as the time when a fish was no longer observable on its stimulus injection location (either away or hiding). For the later parameter, if the test fish was seen more than $3 \mathrm{~m}$ away from its testing location, it was considered absent. This cutoff distance was used, since the observed displacements of territory-holding juvenile Atlantic salmon are generally under this distance (Steingrimsson and Grant 2003). In numerous cases, it was not possible to differentiate between hiding and fleeing; therefore, these two responses were indiscriminately grouped together. Because we cannot assess if certain response variables convey a stronger indication of fright, we interpreted the appearance of any of these behavioural patterns as an alarm response.

\section{Statistical analysis}

Our results were obtained by subtracting the pre-stimulus values from the post-stimulus values, thus giving the difference between the measured behavioural parameters (see above). We tested for any overall effect of $\mathrm{pH}$ with a nested multivariate analysis of variance (MANOVA) using treatment (stream water versus alarm cue) and $\mathrm{pH}$ (neutral versus acidic) as independent variables. We nested the variable stream in their respective $\mathrm{pH}$ level (neutral or acidic). Using subsequent analysis of variance (ANOVA), the effects of $\mathrm{pH}$ 
and stimuli were further investigated. The behavioural response of individuals was directly compared between control and experimental stimuli under neutral and acidic conditions for each year class (parr and YOY).

\section{Results}

For both parr and YOY, a significant effect of treatment that depended on the $\mathrm{pH}$ of the sites was found (MANOVA; treatment: $F_{[5,36]}=8.73, P<0.01 ; \mathrm{pH}: F_{[5,36]}=8.57, P<$ 0.01 ; interaction: $F_{[5,36]}=3.53, P<0.01$ ). For each acidity level (acid or neutral streams), no effect of stream was found on the behavioural response of salmon (i.e., no significant difference in response among the acidic streams and likewise no significant difference in response among the neutral streams; $\left.F_{[1,70]}=0.57 ; P>0.05\right)$. Under neutral conditions, juvenile Atlantic salmon significantly decreased the time spent in motion $\left(t_{13}=3.56, P=0.0035\right.$; Fig. $\left.2 a\right)$ and the number of feeding attempts $\left(t_{13}=3.26, P=0.0061\right.$; Fig. $\left.2 b\right)$, while the time spent on the substrate and the time spent absent (or hiding) from the stimulus injection location increased $\left(t_{13}=3.26, P=0.012\right.$ (Fig. $\left.2 c\right)$ and $t_{13}=3.26, P=$ 0.0061 (Fig. 2d), respectively) when exposed to conspecific alarm cue compared with stream water. However, no significant difference in the number of aggressive interactions between both treatments was found $\left(F_{[1,26]}=4.22 ; P>0.05\right)$. Since the occurrence of such behaviour was rare (mean \pm standard deviation $=0.08 \pm 0.015$ interactions per minute), we did not analyze it any further. Under weakly acidic conditions, however, there was no significant effect of treatment on the behavioural parameters tested (time spent in motion $\left(F_{[1,70]}=1.59 ; P>0.05\right.$; Fig. $\left.2 a\right)$; number of feeding attempts $\left(F_{[1,70]}=2.45 ; P>0.05\right.$; Fig. $\left.2 b\right)$; time spent on the substrate $\left(F_{[1,70]}=0.09 ; P>0.05\right.$; Fig. $\left.2 c\right)$; time spent away from the stimulus injection area $\left(F_{[1,70]}=0.45 ; P>0.05\right.$; Fig. 2d)). As control for potential temporal effects associated with our experimental design, the baseline (prestimulus) scores between stream water and alarm cue stimuli treatments for the neutral and acidic sites were compared using multiples one-way ANOVAs. No significant difference was found in any baseline activity scores between the two groups of sites nor among treatments (multiple one-way ANOVA, $P>0.05)$.

Subsequent one-way ANOVA revealed a significant difference in response intensity in the alarm cue treatment between parr and YOY in the neutral sites in two of the five behavioural measurements, but no significant difference in any of the behavioural measurements in the weakly acidic streams. Parr spent significantly more time on the substrate than YOY did $\left(F_{[1,19]}=8.727, P<0.05\right.$; Fig. $\left.2 c\right)$, but significantly less time absent (or hiding) from the stimulus injection area than YOY did $\left(F_{[1,19]}=7.34, P<0.05\right.$; Fig. $\left.2 d\right)$.

\section{Discussion}

These data demonstrate that juvenile Atlantic salmon found in the studied acidic streams were impaired in their ability to detect and respond to damage-released alarm cues. The response of individuals to alarm cue injections did not differ from stream water injections in any of the acidic sites. Also, the individuals' development stages had no effect on the response intensity in acidic condition, whereas in neutral con-
Fig. 2. Mean ( \pm standard deviation) differences (post-stimulus pre-stimulus) in (a) time in seconds spent in motion, $(b)$ number of feeding attempts, $(c)$ time in seconds spent on the substrate, and $(d)$ time spent in seconds away or hiding for juvenile Atlantic salmon (Salmo salar) exposed to either alarm cues (shaded bars) or stream water (open bars) under neutral ( $\mathrm{pH} \sim 7.0$ ) or acidic ( $\mathrm{pH} \sim 6.0$ ) conditions for young of the year (YOY; left column) and parr (right column).
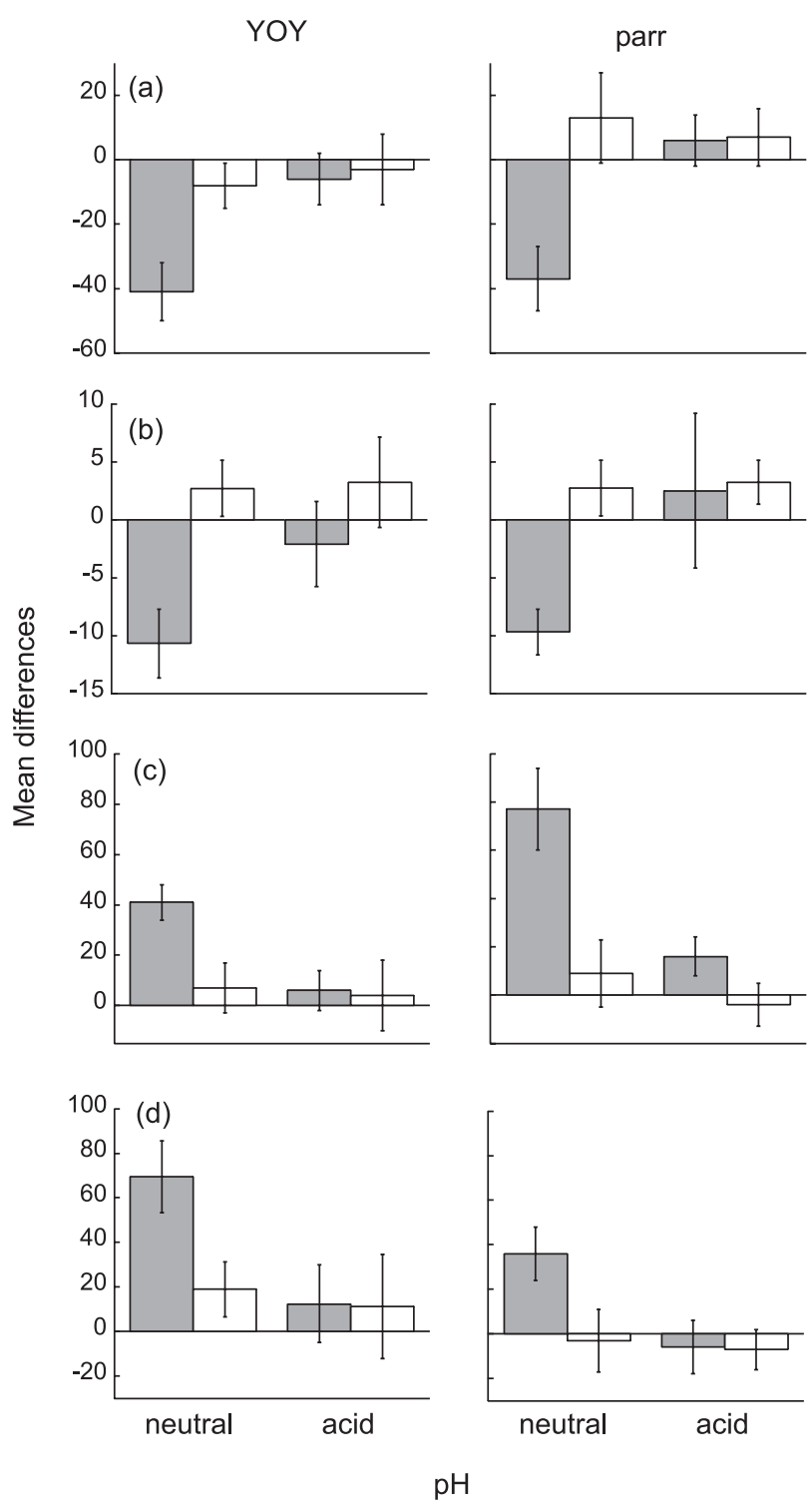

dition, differences occurred. Overall, the findings of this experiment are consistent with the results obtained by Leduc et al. (2004a) and support the prediction that even weak levels of acidity directly affect chemosensory risk assessment.

The loss of alarm function in acidic conditions may be due to the two following mechanisms. First, physiological stress and (or) olfactory damage may account for the apparent lack of response. We did not find, however, any significant difference in mean baseline activity level between individuals of the acidic streams and individuals of the neutral streams. Peterson et al. (1989) found that the threshold of $\mathrm{pH}$ avoidance for Atlantic salmon is $\sim 4.5$, while the most acidic condition we found was a $\mathrm{pH}$ of 5.71 . Hence, the lack 
of difference in baseline behaviour and the relatively weak acidity level suggest that individuals present in both groups of streams were well suited to live in their habitat and did not experience much stress linked to acidity. Alternatively, damage to olfactory receptors may account for the lack of response. Leduc et al. (2004b) have shown that YOY rainbow trout could be conditioned to learn a novel odour when paired with damage-released chemical alarm cues. This learned response, however, did not occur when the odour was paired with acidified alarm cues (at $\mathrm{pH} \sim 6.0$ ). In contrast, acidifying the odour had no effect on the retention of this novel learning as long as the paired alarm cue was not acidified. This result suggests that under weakly acidic conditions, the olfactory function of salmonids is not impaired and thus cannot explain the lack of alarm response. In the second proposed mechanism, the alarm cue may be completely degraded or the concentration of active alarm cues may be reduced below a detectable level because of ambient pH (Leduc et al. 2003). Several authors have shown that concentration of alarm cues below some population-specific threshold fails to elicit an overt antipredator response (Brown et al. 2001a; Mirza and Chivers 2003; Roh et al. 2004). We do not know the concentration of active alarm cue presented to our test fish; therefore, we cannot exclude the effect of covert response (i.e., a nonobservable response elicited by a concentration level of alarm cues that would be under the minimal concentration threshold to elicit an observable response; Brown et al. 2001b; Mirza and Chivers 2003). Leduc et al. (2004b) have shown that no acquired recognition of a novel odour paired with an alarm cue occurred under weakly acidic conditions, while recognition did occur under neutral conditions. These results suggest that a complete degradation of the alarm cues occurs under acidified conditions.

It is now well established that wild Atlantic salmon populations have steadily been declining over the last three decades (Parrish et al. 1998). The explanation of this decline includes a synergetic interaction of many deleterious effects, including invasion of farmed salmon, overfishing, habitat destruction, pollution (including acidification), and changing oceanic conditions (Parrish et al. 1998; Fleming et al. 2000). While many salmonid species are suited to live in a weakly acidic condition (Scott and Crossman 1973; Rosseland et al. 2001), there may be an indirect cost linked to increased predation success of predators. It was hypothesized that predation pressure is reduced in acidic conditions with predatory fish absent or reduced because of ambient $\mathrm{pH}$ (Bendell and McNicol 1987). We found in both our acidic and neutral streams several fish species that are known predators to juvenile Atlantic salmon, such as brook trout, slimy sculpin (Cottus cognatus), and $2+$ Atlantic salmon parr (Henderson and Letcher 2003). Moreover, predation pressure on juvenile Atlantic salmon in their nursery streams may come from birds (Wood 1987) and mammals (Heggenes and Borgstrøm 1988). Hence, the range of potential predators may not be directly affected by ambient acidity. As such, the observed alarm cue impairment could likely have major fitness costs linked to increased predation success of juvenile salmon's predators.

Fishes present in the acidified environment should face a considerable disadvantage compared with fishes living in neutral conditions, owing to their impaired ability to detect damage-released alarm cues. Responding to alarm cues of both conspecifics and heterospecifics has been shown to increase the survival of prey individuals in encounters with live predators (Mirza and Chivers 2000; Chivers et al. 2002). Likewise, the identity of a novel predator is learned faster from the detection of damage-released alarm cues than from visual cues (Brown et al. 1997). This difference in recognition time should be especially valid in a structurally complex environment, as is often found in many nursery streams used by Atlantic salmon. Hence, sublethal effects associated with acidity may exist for juvenile salmon, as for prey fishes in general. Aside from prey fishes, several taxa of aquatic vertebrates and invertebrates including amphibians, arthropods, and flatworms have been shown to respond to chemical alarm cues to mediate predation risk (Bouwma and Hazlett 2001; Kiesecker et al. 1996; Wisenden and Millard 2001). As such, anthropogenic acidification of natural water bodies may also influence a wide variety of aquatic organisms in their ability to use chemical alarm cues to assess predation risk.

As aquatic waterways may suffer from depleted buffering capacities in many areas affected by acid precipitations (Stoddard et al. 1999; Clair et al. 2004), deleterious effects on juvenile salmonid populations may arise. Therefore, even slight increases in acid precipitation may affect the ability of prey individuals to assess local predation risk via chemosensory cues, in spite of populations' tolerance to acidity. It is of interest to mention that other anthropogenic pollutants affect chemosensory risk assessment in fishes (McPherson et al. 2004; Scholz et al. 2000; Scott et al. 2003). As such, measures to effectively avoid deleterious direct and indirect effects linked to anthropogenic pollution in natural waterways should aim at looking at an integrated approach (Parrish et al. 1998). Changes in the chemistry of aquatic ecosystems may hinder juvenile salmonids from using an ecologically important source of information on local predation risk. Should it be the case, this may contribute to hinder wild Atlantic salmon stocks in recovering from a depleted state.

\section{Acknowledgements}

The authors thank Rick A. Cunjak for providing helpful suggestions and field support, James W. Grant and Emma Despland for helpful comments on the statistical method, and two anonymous reviewers to for comments on the manuscript. Concordia University and the Natural Sciences and Engineering Research Council of Canada (NSERC) provided the financial support to G. Brown and an NSERC post-graduate studies (PGS) D2 Scholarship to A. Leduc. All work reported herein was conducted in accordance with Concordia University Animal Care Committee protocol No. AC-2002-BROW. This paper is Contribution No. 87 to the Catamaran Brook Habitat Research Project.

\section{References}

Åtland, A. 1998. Behavioural responses of brown trout, Salmo trutta, juveniles in concentration gradients of $\mathrm{pH}$ and $\mathrm{Al}-\mathrm{a}$ laboratory study. Environ. Biol. Fishes, 53: 331-334. 
Bendell, B.E., and McNicol, D.K. 1987. Cyprinid assemblages and the physical and chemical characteristics of small northern Ontario lakes. Environ. Biol. Fishes, 19: 229-234.

Berejikian, B.A., Smith, R.J.F., Tezak, P.E., Schroder, P.E., and Knudsen, C.M. 1999. Chemical alarm signals and complex hatchery rearing habitats affect antipredator behavior and survival of chinook salmon (Oncorhynchus tshawytscha) juveniles. Can. J. Fish. Aquat. Sci. 56: 830-838.

Bouwma, P., and Hazlett, B.A. 2001. Integration of multiple predator cues by the crayfish Orconectes propinquus. Anim. Behav. 61: 771-776.

Brown, G.E. 2003. Learning about danger: chemical alarm cues and local risk assessment in prey fishes. Fish Fish. 4: 227-234.

Brown, G.E., and Smith, R.F.J. 1997. Conspecific skin extract elicits antipredator responses in juvenile rainbow trout (Oncorhynchus mykiss). Can J. Zool. 75: 1916-1922.

Brown, G.E., and Smith, R.F.J. 1998. Acquired predator recognition in juvenile rainbow trout (Oncorhynchus mykiss): conditioning hatchery-reared fish to recognize chemical cues of a predator. Can. J. Fish. Aquat. Sci. 55: 611-617.

Brown, G.E., Chivers, D.P., and Smith, R.J.F. 1997. Differential learning rates of chemical versus visual cues of a northern pike by fathead minnows in a natural habitat. Environ. Biol. Fishes, 49: 89-96.

Brown, G.E., Adrian, J.C., Jr., Patton, T., and Chivers, D.P. $2001 a$. Fathead minnows learn to recognize predator odour when exposed to concentrations of artificial alarm pheromone below their behavioural-response threshold. Can. J. Zool. 79: 2239-2245.

Brown, G.E., Adrian, J.C., Jr., and Shih, M.L. 2001b. Behavioural responses of fathead minnows to hypoxanthine- $3-\mathrm{N}$-oxide at varying concentrations. J. Fish Biol. 58: 1465-1470.

Brown, G.E., Adrian, J.C., Jr., Lewis, M.G., and Tower, J.M. 2002. The effects of reduced $\mathrm{pH}$ on chemical alarm signaling in ostariophysan fishes. Can. J. Fish. Aquat. Sci. 59: 1331-1338.

Chivers, D.P., and Smith, R.J.F. 1998. Chemical alarm signaling in aquatic predator-prey systems: a review and prospectus. Ecoscience, 5: 315-321.

Chivers, D.P., Brown, G.E., and Smith, R.J.F. 1996. Evolution of alarm signals: attracting predators benefits alarm signal senders. Am. Nat. 148: 649-659.

Chivers, D.P., Mirza, R.S., and Johnston, J.G. 2002. Learned recognition of heterospecific alarm cues enhances survival during encounters with predators. Behaviour, 139: 929-938.

Clair, T.A., Dennis, I.F., Amiro, P.G., and Cosby, B.J. 2004. Past and future chemistry changes in acidified Nova Scotian Atlantic salmon (Salmo salar) rivers: a dynamic modeling approach. Can. J. Fish. Aquat. Sci. 61: 1965-1975.

Doka, S.E., McNicol, D.K., Mallory, M.L., Woog, I., Minns, C.K., and Yan, N.D. 2003. Assessing potential for recovery of biotic richness and indicator species due to changes in acidic deposition and lake $\mathrm{pH}$ in five areas of southeastern Canada. Environ. Monit. Assess. 88: 53-101.

Fleming, I.A., Hindar, K., Mjølnerød, I.B., Jonsson, B., Balstad, T., and Lamberg, A. 2000. Lifetime success and interactions of farm salmon invading a native population. Proc. R. Soc. Lond. B Biol. Sci. 267: 1517-1523.

Grant, J.W.A., Steingrimsson, S.Ó., Keeley, E.R., and Cunjak, R.A. 1998. Implications of territory size for the measurement and prediction of salmonid abundance in streams. Can. J. Fish. Aquat. Sci. 55: 181-190.

Guerold, F., Boudot, J.-P., Jacquemin, G., Vien, D., Merlet, D., and Rouiller, J. 2000. Macroinvertebrate community loss as a result of headwater stream acidification in the Vosges Mountains (N-E France). Biodivers. Conserv. 9: 767-783.
Gunn, J.M., and Noakes, D.L.G. 1986. Avoidance of low pH and elevated $\mathrm{Al}$ concentration by brook charr (Salvelinus fontinalis) alevins in laboratory tests. Water Air Soil Pollut. 30: 497-503.

Heggenes, J., and Borgstrøm, R. 1988. Effect of mink, Mustela vison Schreber, predation on cohorts of juvenile Atlantic salmon, Salmo salar L., and brown trout, S. trutta L., in three small streams J. Fish Biol. 33: 885-886.

Henderson, N.J., and Letcher, B.H. 2003. Predation on stocked Atlantic salmon (Salmo salar) fry. Can. J. Fish. Aquat. Sci. 60: 32-42.

Holt, C.A., Yan, N.D., and Somers, K.M. 2003. pH 6 as threshold use in critical load modeling for zooplankton community change with acidification in lakes of south-central Ontario: accounting for morphometry and geography. Can. J. Fish. Aquat. Sci. 60: 151-158.

Ikuta, K., Munakata, A., Aida, K., Amano, M., and Kitamura, S. 2001. Effects of low $\mathrm{pH}$ on upstream migratory behavior in land-locked sockeye salmon Oncorhynchus nerka. Water Air Soil Pollut. 130: 99-106.

Jeffries, D.S., Lam, D.C.L., Wong, I., and Moran, M.D. 2000. Assessment of changes in lake $\mathrm{pH}$ in southeastern Canada arising from present levels and expected reductions in acidic deposition. Can. J. Fish. Aquat. Sci. 57: 40-49.

Johnson, D.W., and Webster, D.A. 1977. Avoidance of low pH in selection of spawning sites by brook trout (Salvelinus fontinalis). J. Fish. Res. Board Can. 34: 2215-2218.

Kiesecker, J.M., Chivers, D.P., and Blaustein, A.R. 1996. The use of chemical cues in predator recognition by western toad (Bufo boreas) tadpoles. Anim. Behav. 52: 1237-1245.

Kitamura, S., and Ituka, K. 2001. Effects of acidification on salmonid spawning behavior. Water Air Soil Pollut. 130: 875-880.

Lacroix, G.L., Gordon, D.J., and Johnston, D.J. 1985. Effects of low environmental $\mathrm{pH}$ on the survival, growth, and ionic composition of postemergent Atlantic salmon (Salmo salar). Can. J. Fish. Aquat. Sci. 42: 768-775.

Leduc, A.O.H.C., Noseworthy, M.K., Adrian, J.C., Jr., and Brown, G.E. 2003. Detection of conspecific and heterospecific alarm signals by juvenile pumpkinseed under weak acidic conditions. J. Fish Biol. 63: 1331-1336.

Leduc, A.O.H.C., Kelly, J.M., and Brown, G.E. 2004a. Detection of conspecific alarm cues by juvenile salmonids under neutral and weakly acidic conditions: laboratory and field tests. Oecologia, 139: 318-324.

Leduc, A.O.H.C., Ferrari, M.C.O., Kelly, J.M., and Brown, G.E. 2004b. Learning to recognize novel predators under weakly acidic conditions: the effects of reduced $\mathrm{pH}$ on acquired predator recognition by juvenile rainbow trout. Chemoecology, 14: 107-112.

Magurran, A.E., Irving, P.W., and Henderson, P.A. 1996. Is there a fish alarm pheromone? A wild study and critique. Proc. R. Soc. Lond. B Biol. Sci. 263: 1551-1556.

Mallory, M.L., McNicol, D.K., Cluis, D.A., and Laberge, C. 1998. Chemical trends and status of small lakes near Sudbury, Ontario, 1983-1995: evidence of continued chemical recovery. Can. J. Fish. Aquat. Sci. 55: 63-75.

McPherson, T.D., Mirza, R.S., and Pyle, G.G. 2004. Responses of wild fishes to alarm chemicals in pristine and metal-contaminated lakes. Can. J. Zool. 82: 694-700.

Mirza, R.S., and Chivers, D.P. 2000. Predator-recognition training enhances survival of brook trout: evidence from laboratory and field-enclosure studies. Can. J. Zool. 78: 2198-2208.

Mirza, R.S., and Chivers, D.P. 2001a. Are chemical alarm cues conserved within salmonid fishes? J. Chem. Ecol. 27: 1641-1655.

Mirza, R.S., and Chivers, D.P. 2001b. Do chemical alarm signals enhance survival of aquatic vertebrates? An analysis of the cur- 
rent research paradigm. In Chemical signals in vertebrates. Vol. 9. Edited by A. Marchlewska-Koj, J.J. Lepri, and D. Müller-Schwarze. Kluwer, New York. pp. 19-26.

Mirza, R.S., and Chivers, D.P. 2002. Brook char (Salvelinus fontinalis) can differentiate chemical alarm cues produced by different age/size classes of conspecifics. J. Chem. Ecol. 28: $555-564$.

Mirza, R.S., and Chivers, D.P. 2003. Response of juvenile rainbow trout to varying concentrations of chemical alarm cue: response thresholds and survival during encounters with predators. Can. J. Zool. 81: 88-95.

Parrish, D.L., Behnke, R.J., Gephard, S.R., McCormick, S.D., and Reeves, G.H. 1998. Why aren't there more Atlantic salmon (Salmo salar)? Can. J. Fish. Aquat. Sci. 55(Suppl. 1): 281-287.

Peterson, R.H., Coombs, K., Power, J., and Paim, U. 1989. Response of several fish species to $\mathrm{pH}$ gradients. Can. J. Zool. 67: $1566-1572$.

Robinson, G.D., Dunson, W.A., Wright, J.E., and Mamolito, G.E. 1976. Differences in low $\mathrm{pH}$ tolerance among strains of brook trout (Salvelinus fontinalis). J. Fish Biol. 8: 5-17.

Roh, E., Mirza, R.S., and Brown, G.E. 2004. Quality or quantity? The role of donor condition in the production of chemical alarm cues in juvenile convict cichlids. Behaviour, 41: 1235-1248.

Rosseland, B.O., Kroglund, F., Staurnes, M., Hindar, K., and Kvellestad, A. 2001. Tolerance to acid water among strains and life stages of Atlantic salmon (Salmo salar L.). Water Air Soil Pollut. 130: 899-904.

Schindler, D.W. 1988. Effects of acid rain on freshwater ecosystems. Science (Washington, D.C.), 239: 149-157.

Scholz, N.L., Truelove, N.K., French, B.L., Berejikian, B.A., Quinn, T.P., Casillas, E., and Collier, T.K. 2000. Diazinon disrupts antipredator and homing behaviors in chinook salmon (Oncorhynchus tshawytscha). Can. J. Fish. Aquat. Sci. 57: 1911-1918.

Scott, W.B., and Crossman, E.J. 1973. Freshwater fishes of Canada. Fish. Res. Board Can. Bull. No. 184.

Scott, G.R., Sloman, K.A., Rouleau, C., and Wood, C.M. 2003. Cadmium disrupts behavioural and physiological response to alarm substance in juvenile rainbow trout (Oncorhynchus mykiss). J. Exp. Biol. 206: 1779-1790.

Smith, R.J.F. 1992. Alarm signal in fishes. Rev. Fish Biol. Fish. 2: 33-63.

Smith, R.J.F. 1997. Does one result trump all others? A response to Magurran, Irving and Henderson. Proc. R. Soc. Lond. B Biol. Sci. 264: 445-450.

Smith, R.J.F. 1999. What good is smelly stuff in the skin? Cross function and cross taxa effects in fish "alarm substances". In Advances in chemical signals in vertebrates. Edited by R.E. Johnston, D. Müller-Schwarze, and P.W. Sorensen. Kluwer, New York. pp. 475-487.

Steingrimsson, S.Ó., and Grant, J.W.A. 2003. Patterns and correlates of movement and site fidelity in individually tagged youngoff-the-year Atlantic salmon (Salmo salar). Can. J. Fish. Aquat. Sci. 60: 193-202.

Stoddard, J.L., Jeffries, D.S., Lukewille, A., Clair, T.A., Dillon, P.J., Driscoll, C.T., Forsius, M., Johannessen, M., Kahl, J.S., Kellogg, J.H., Kemp, A., Mannio, J., Monteith, D., Murdoch, P.S., Partick, S., Rebsdorf, A., Skjelkvale, B.L., Stainton, M.P., Traaen, T., van Dam, H., Webster, K.E., Wieting, J., and Wilander, A. 1999. Regional trends in aquatic recovery from acidification in North America and Europe. Nature (London), 401: $575-578$.

Wisenden, B.D. 2000. Olfactory assessment of predation risk in aquatic environment. Phil. Trans. R. Soc. Lond. B Biol. Sci., 355: $1205-1208$.

Wisenden, B.D., and Millard, M.C. 2001. Aquatic flatworms use chemical cues from injured conspecifics to assess predation risk and to associate risk with novel cues. Anim. Behav. 62: 761766.

Wisenden, B.D., Vollbrecht, K.A., and Brown, J.L. 2004. Is there a fish alarm cue? Affirming evidence from a wild study. Anim. Behav. 67: 59-67.

Wood, C.C. 1987. Predation of juvenile Pacific salmon by the common merganser (Mergus merganser) on eastern Vancouver Island. II. Predation of stream-resident juvenile salmon by merganser broods. Can. J. Fish. Aquat. Sci. 44: 950-959. 